\title{
How to centre the umbilicus following rectus abdominous myocutaneous flap transfers
}

\author{
J Michael Drever MD FRCSC, J Habiballah MBBS FRCSC \\ Etobicoke, Ontario
}

\begin{abstract}
JM Drever, J Habiballah. How to centre the umbilicus following rectus abdominous myocutaneous flap transfers. Can J Plast Surg 1998;6(1):37-40.

Rectus abdominous myocutaneous and transverse rectus abdominous myocutaneous (TRAM) flaps are increasingly used for breast reconstruction. The navel tends to deviate to one side, mostly in unilateral pedicle cases, when pulled by the muscle closure side. These sequela can be avoided by amputating the umbilicus and reconstructing a new one with a ' $U$ '-shaped flap or by dragging navels that have a long stalk to the midline. To avoid scar contracture, a ' $V$ '-shaped flap is inset into the umbilicus.
\end{abstract}

Key Words: Breast reconstruction, Rectus abdominous myocutaneous flaps, Torsoplasty, Transverse rectus abdominous myocutaneous (TRAM) flaps, Umbilicoplasty, Umbilicus

\section{Comment centrer l’ombilic après un transfert de lambeaux myocutanés du grand droit}

RÉSUMÉ : Les lambeaux myocutanés du grand droit et du transverse sont de plus en plus utilisés pour la reconstruction mammaire. Le nombril a tendance à dévier d'un côté, surtout dans les cas de pédicules unilatéraux du côté du muscle refermé. Cette séquelle peut être évitée par une amputation de l'ombilic et la reconstruction d'un nouvel ombilic au moyen d'un lambeau en U ou en déplaçant les ombilics qui ont un pédicule suffisamment long. Pour éviter la contracture de la cicatrice, on insère un lambeau en $\mathrm{V}$ dans l'ombilic.

A fter transferring a rectus abdominous myocutaneous flap and closure of the rectus sheath, the surgeon may face one of the following predicaments.

- If a mesh was used to replace the removed fascia, the umbilicus will usually stay at or near the midline; the same situation occurs for bilateral closure when the umbilicus is brought out through the mesh. In these cases the ' $\mathrm{V}$ ' flap umbilicoplasty is performed.

- If the fascial closure was done directly, the umbilicus will invariably be pulled to the side of the closure, in which case two situations can arise: the umbilical stalk is short and will not reach the midline (it can simply be amputated at its base, and the 'U'-shaped

Correspondence and reprints: Dr JM Drever, 135 Queen's Plate Drive, Suite 560, Etobicoke, Ontario M9W 6V1. Telephone 416-745-8898, fax 416-745-8899, e-mail michael.drever@sympatico.ca neoumbilicoplasty be performed); or the stalk can be stretched to reach the midline, entailing the ' $\mathrm{V}$ ' flap umbilicoplasty.

- If the umbilicus is not present either preoperatively or transferred with the flap, the ' $U$ ' neoumbilicoplasty is performed.

TECHNIQUE \#1 - THE 'U' NEOUMBILICOPLASTY Following closure of the rectus sheath, the position of the umbilicus and adequacy of stalk length are assessed by gentle traction (Figure 1). If the umbilical stalk does not reach the midline it is amputated, the residual hole is sutured and the abdominal skin is closed in the regular fashion.

To reconstruct a neoumbilicus, a superiorly or inferiorly based ' $U$ '-shaped flap is designed in the midline at the transiliac crest level. The flap measures $1.5 \mathrm{~cm}$ in width and length, and is dissected at the deep dermal level leaving no fat attached (Figure 2). Then a core of subcutaneous fat with a 


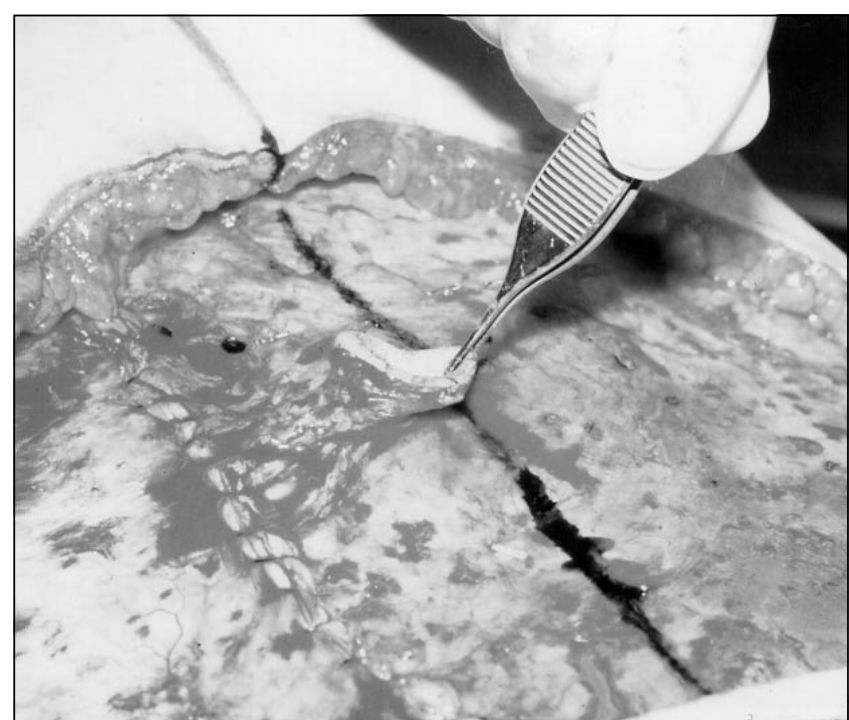

Figure 1) An attempt is made to drag the umbilical stalk to the midline; if the centre of the cylinder does not reach it, then the umbilical stalk is amputated and the ' $U$ ' neoumbilicoplasty is performed

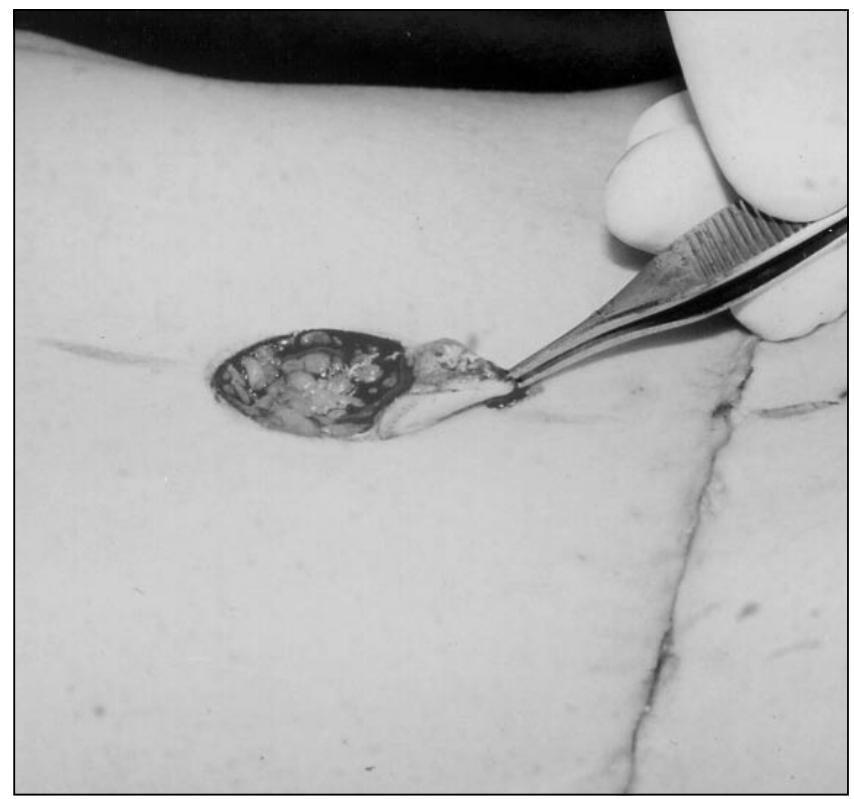

Figure 2) ' $U$ '-shaped flap measuring $15 \times 15 \mathrm{~mm}$. The flap is raised at the dermal level

diameter of 3 to $5 \mathrm{~cm}$ is excised to create a normal-appearing central depression and to allow the little flap to reach the fascia more easily (Figure 3 ). The undersurface of the ' $U$ ' dermal flap is advanced distally into the base of the crater and sutured to the underlying fascia with 000 slow reabsorbing suture (Figure 4). The free edge of the abdominal skin is also sutured to the fascia and to the edge of the flap only at 3:00, 6:00 and 9:00, leaving small spaces between the sutures to provide drainage. Sofratulle packing is inserted in the depth of the neoumbilicus and a dressing is applied over it.

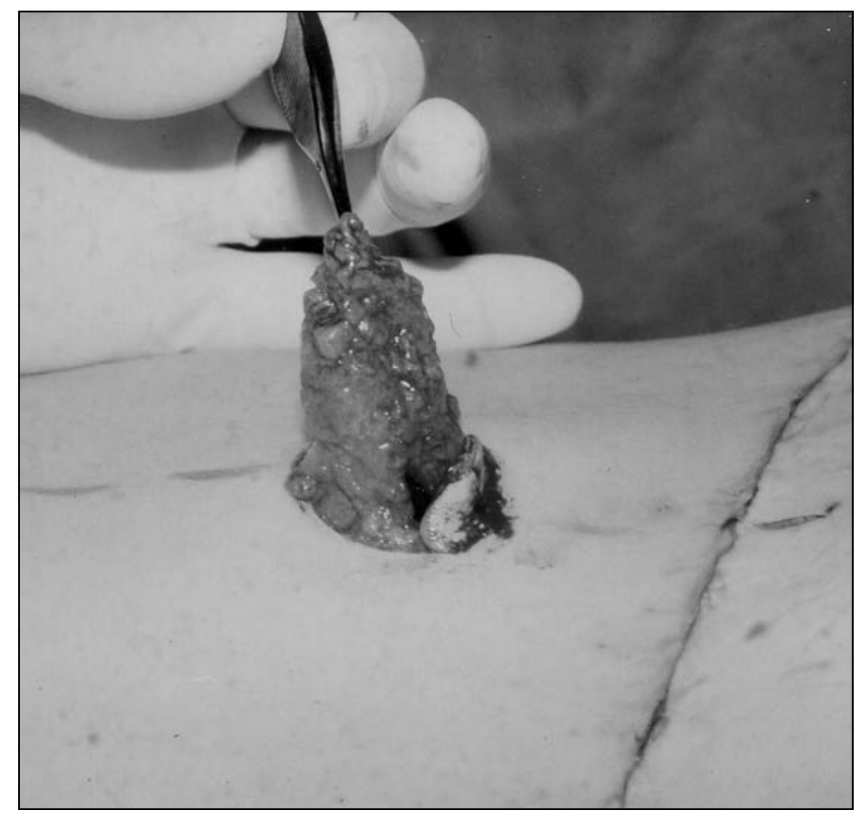

Figure 3) A core of fat, 3 to $5 \mathrm{~cm}$ in diameter, is excised to create the natural umbilical region depression

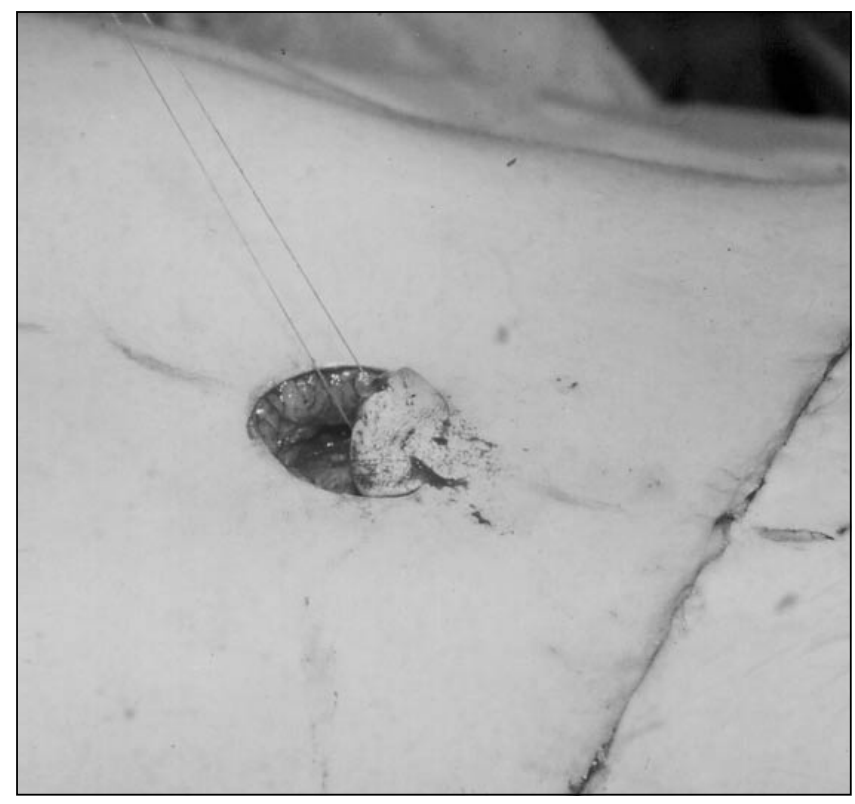

Figure 4) The middle of the dermal flap is sutured to the fascia below, and three other stitches are placed at the 3:00, 6:00 and 9:00 positions that include the abdominal skin, the underlying fascia and the dermis flap edge. The openings between them are left to provide drainage

\section{TECHNIQUE \#2 - THE 'V'-SHAPED UMBILICOPLASTY}

When the umbilicus reaches the midline with ease, the umbilical location is marked on the abdominal wall skin and a triangular flap is designed with each limb measuring $15 \mathrm{~mm}$.

The ' $\mathrm{V}$ ' flap is also raised in a subdermal plane and the core of subcutaneous fat is excised. Then the umbilical cylinder is exteriorized through the flap opening and divided down to its fundus. The apex of the flap is sutured to the base of the umbilical cylinder. The edges of the flap are sutured to 


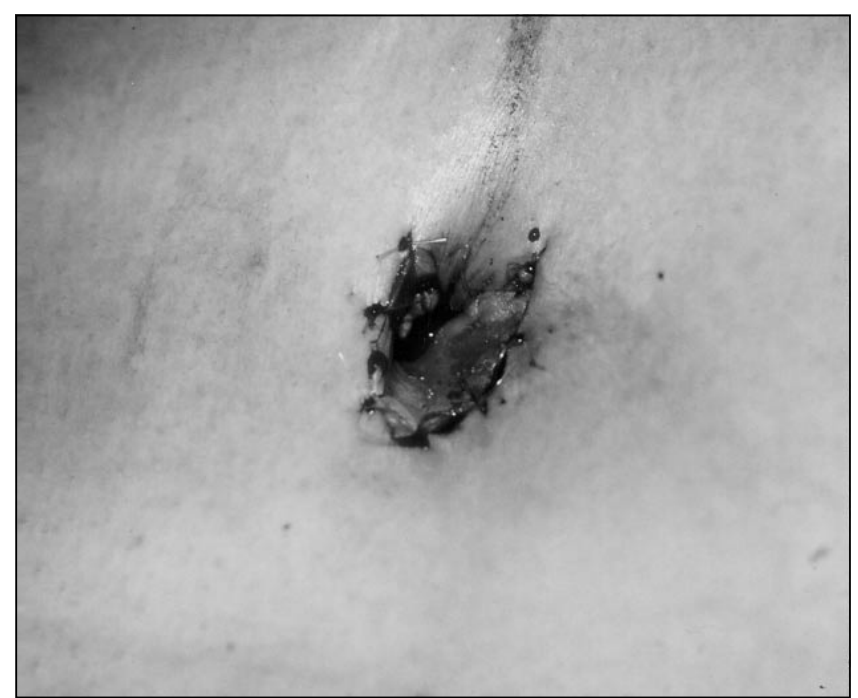

Figure 5) The ' $V$ ' umbilicoplasty is done when the umbilical stalk reaches the midline

each side of the bisected umbilical cylinder, leaving a quasiheart-shaped suture line that will prevent a circular contracture (Figure 5).

\section{DISCUSSION}

Familiarity with the normal variations of the aesthetically pleasing navel is an important detail that is essential for obtaining a cosmetically acceptable abdominal wall.

The umbilicus originates as a scar when the umbilical cord sloughs. It is normally located in the midline on a line connecting the iliac crests or just 2 to $4 \mathrm{~cm}$ above that. Radiographically it is usually situated over the disc between the third and fourth lumbar vertebrae.

The shape of the umbilicus varies with age and parity of the patient; it is flat and somewhat vertical in the young lean nulliparous women but has a transverse appearance in the multiparous patient. In heavy patients the presence of periumbilical fat gives it a deep and wide appearance, whereas in the thin patient it may be shallow or protuberant.

Following a transverse rectus abdominous myocutaneous (TRAM) procedure and closure of the rectus sheath, the status and position of the umbilicus may deviate to the closure side or be taken with the flap requiring reconstruction.

When the umbilicus is left in situ and can reach the midline, it is exteriorized in the traditional fashion. The choice of skin incision for delivering depends on the surgeon's preference. We have found that the use of the ' $V$ ' flap inset into the umbilical cylinder has produced an aesthetically pleasing umbilicus and no scar contracture. The flap can be based superiorly to produce the superior hooding that is seen in multiparous patients. It can also be based laterally to produce the vertically shaped youthful umbilicus. A modification of the original ' $V$ ' shape into a ' $U$ ' shape was also reported to have good results, producing a deep round umbilicus with a barely visible scar. We also do this procedure in the abdominal dermolipectomies.

If the umbilicus can not reach the midline we recommend
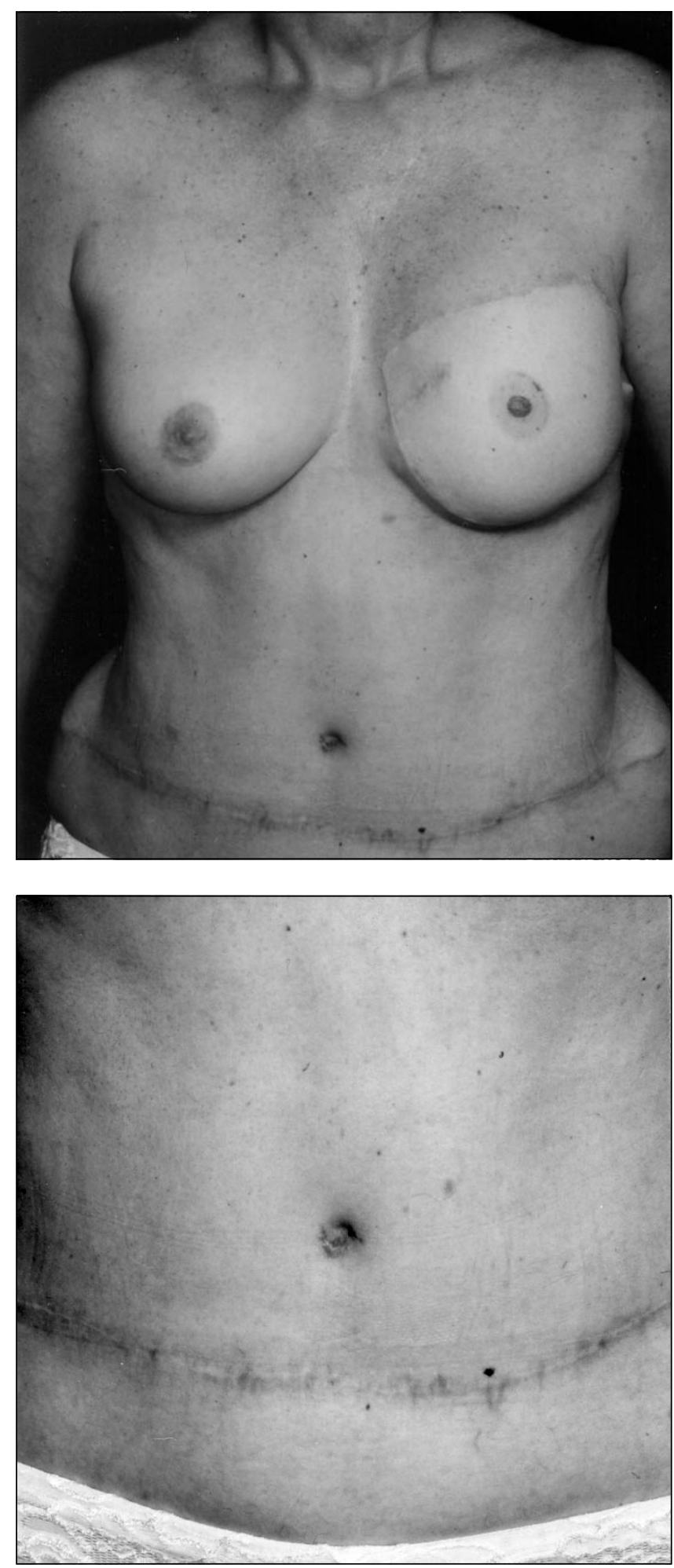

Figure 6) Patient and close-up nine months after a transverse rectus abdominous myocutaneous breast reconstruction with a ' $U$ ' neoumbilicoplasty

amputating it. Attempts to exteriorize it through a convenient lateral location may result in a laterally positioned navel that is not acceptable and harder to correct than the higher or lower ones. Such deformities will be easily noticeable and have been the cause of legal actions. 
Reefing the opposite side of the rectus sheath has been described to correct the umbilical deviation, but this technique is not always feasible because a tight rectus sheath is usually seen following a TRAM flap, so further reefing of the opposite fascia is difficult and may tear the sutures or cause persistent postoperative pain. On the other hand, releasing fascial incisions may produce an increased incidence of abdominal bulges or hernias because they interrupt the function of the oblique muscles (1).

For an umbilicus that is to be amputated, several neoumbilicoplasty procedures have been described - varying from local flaps to flaps with composite grafts or with skin grafts (2-14). The ' $U$ ' neoumbilicus is an easy technique that can be used immediately and, in our hands, has produced very satisfactory long term results (Figure 6).

\section{REFERENCES}

1. Drever JM, Hodson-Walker N. Closure of the donor defect for breast reconstruction with rectus abdominous myocutaneous flaps. Plast Reconstr Surg 1985;76:558-65.

2. Baroudi R. Umbilicoplasty. Clin Plast Surg 1975;2:431-48.

3. Delerm A. Refinements in abdominoplasty with emphasis on reimplantation of the umbilicus. Plast Reconstr Surg 1982;70:632-7.
4. Pickrell KL. Reconstructive surgery of the abdominal wall and back. In: Converse JM, ed. Reconstructive Plastic Surgery. Philadelphia: WB Saunders, 1967;64:1940.

5. Teimourian B, Marefat S. Body contouring with suction-assisted lipectomy. In: Cohen M, ed. Mastery of Plastic and Reconstructive Surgery. Boston: Little, Brown \& Co, 1994;1:2198.

6. de Lacerda DJ, Martins DM, Marques A, Brenda E, de Moura-Andrews J. Umbilicoplasty for the abdomen with a thin adipose layer. Br J Plast Surg 1994;47:386-7.

7. Juri J, Juri C, Raiden G. Reconstruction of the umbilicus in abdominoplasty. Plast Reconstr Surg 1979;63:580-2.

8. Baroudi R, Carvalho C. Complications of abdominoplasty. In: Lewis JR Jr, ed. The Art of Aesthetic Plastic Surgery. Boston: Little, Brown \& Co, 1989;II:1033.

9. Miller MJ, Balch CM. "Iris" technique for immediate umbilical reconstruction. Plast Reconstr Surg 1993;92:754-6.

10. Marconi F. Reconstruction of the umbilicus: a simple technique. Plast Reconstr Surg 1995;95:1115-7.

11. Kirianoff TG. Making a new umbilicus when none exists. Case report. Plast Reconstr Surg 1978;61:603-4.

12. Itoh Y, Arai K. Umbilical reconstruction using a cone-shaped flap. Ann Plast Surg 1992;28:335-8.

13. Matsuo K, Kondoh S, Hirose T. A simple technique for reconstruction of the umbilicus, using a conchal cartilage composite graft. Plast Reconstr Surg 1990;86:149-51.

14. Baroudi R. Abdominoplasty. In: Lewis JR Jr, ed. The Art of Aesthetic Plastic Surgery. Boston: Little, Brown \& Co, 1989;II:1017. 